\title{
TfR Binding Peptide Screened by Phage Display Technology - Characterization to Target Cancer Cells
}

\author{
Xiaoyong Dai ${ }^{1}$, Yaoling Xiong ${ }^{1}$, Dandan $\mathrm{Xu}^{1}$, Linyan $\mathrm{Li}^{1}$, Zhijian $\mathrm{Su}^{2}$, Qihao \\ Zhang ${ }^{2}$, and Qing Zheng ${ }^{1 *}$ \\ ${ }^{1}$ College of Pharmacy, ${ }^{2}$ Department of Biopharmaceutical Research and Development Centre, Jinan University, Guangzhou \\ 510632, Guangdong, People's Republic of China
}

*For correspondence: Email: tzhengq@jnu.edu.cn; Tel: 86-020-85226518

Received: 13 July 2013

Revised accepted: 2 February 2014

\begin{abstract}
Purpose: To screen an hTfR affinity peptide and investigate its activity in vitro.

Methods: hTfR affinity phage clones were screened from 7-mer phage display library, and their binding ability evaluated by enzyme-linked immunosorbent assay (ELISA). A competitive assay was performed to discover the peptide BP9 (BP9) binding site on the cells. The inhibitory effect of BP9 on the cells was determined using thiazolyl blue (MTT) assay. EGFP-BP9 fusion protein was expressed in E. coli, and its binding and localization on cells were determined by fluorescence microscopy and confocal microscopy, respectively.

Results: After three rounds of panning, recovery efficiency was 48-fold higher than that of the first round. The peptide BP9 sharing 2 identical amino acids to Tf showed high-affinity to hTfR, and possessed strong proliferation inhibition ratio on different tumour cells of $70 \%$ (HepG2 cells)/77\% (SMMC-7221 cells) at a concentration of $0.1 \mathrm{mM}$, and $85 \%$ (HepG2 cells)/81 \% (SMMC-7221 cells) at a concentration of $0.001 \mathrm{mM}$ for $48 \mathrm{~h}$. The recombinant protein EGFP-BP9 could bind to tumour cells and gain entry via the endocytic pathway.

Conclusion: BP9 can bind to TfR and inhibit the proliferation of the tumour cells over-expressing TfR. The DNA sequence coding for BP9 was able to target the macromolecule to combine with TfR. BP9 may possess potential applications in cancer therapy.
\end{abstract}

Keywords: Peptide, hTfR, Transferrin receptor, Phage display technology, Enhanced green fluorescence protein, Target, Cancer cells

Tropical Journal of Pharmaceutical Research is indexed by Science Citation Index (SciSearch), Scopus, International Pharmaceutical Abstract, Chemical Abstracts, Embase, Index Copernicus, EBSCO, African Index Medicus, JournalSeek, Journal Citation Reports/Science Edition, Directory of Open Access Journals (DOAJ), African Journal Online, Bioline International, Open-J-Gate and Pharmacy Abstracts

\section{INTRODUCTION}

Phage display is a selection technique in which a library of peptide or protein variants is expressed on the outside of a phage virion, while the genetic material encoding each variant resides on the inside [1]. Phage display technology shows good prospects in targeted therapies, and peptides are promising molecules to selectively deliver imaging or therapeutic agents to tumours. A number of peptides have been identified by phage display for targeting different tumors and cell types [2-4]. Among these, tumor homing peptides RGD [2,5] and NGR [6] sequences have received particular attention. The experimental results show that these peptides can significantly increase the enrichment of the drug in the target tissue, improve efficacy, and reduce the side effects of drugs [7-9].

The transferrin receptor (TfR) has been reported to be ubiquitously expressed and is overexpressing 100-fold in many tumour cells and brain capillary endothelial cells [10]. Because of its expression pattern and pathway 
characteristics, the $\mathrm{hTfR}$ is an attractive target for therapeutics for tumour and central nervous system diseases.

At present, scientists have succeeded in connecting many therapeutic molecules to hTfR's natural ligand transferrin (Tf) and to hTfR antibody (OX26), and they have achieved good results in oncology and central nervous system diseases [11,12]. However, the high concentration of endogenous $\mathrm{Tf}$ and the relatively high molar weight of $\mathrm{Tf}$ in blood make TfR difficult for the construction of drug delivery systems [13]. In order to identify peptides that can prevent TfR from binding to its ligand Tf, we have attempted in this study to isolate a highaffinity from a 7-mer phage display library, and the functions of peptide BP9 were further studied to evaluate its therapeutic potential in cancer treatment.

\section{EXPERIMENTAL}

\section{Cell lines and regents}

BP9 peptide and FITC-BP9 peptide were synthesized by Guangzhou Teli biotechnology co., Ltd. HepG2, SMMC-7721 and L-O2 cell lines were purchased from the Type Culture Collection of the Chinese Academy of Sciences (Shanghai, China). They were all maintained at $37^{\circ} \mathrm{C}$ in a humidified atmosphere of $5 \% \mathrm{CO}_{2}$ and cultured in RPMI-1640 supplemented with $10 \%(\mathrm{v} / \mathrm{v})$ FBS. The hTfR (R\&D, USA) was used as a target molecule. The Ph.D. $-7^{\mathrm{TM}}$ Phage Display Peptide Library kit (New England Biolabs, Beverly, MA, USA) was used to screen specific peptides binding to hTfR. E. coli ER2738 (New England Biolabs) was used for M13 phage propagation.

\section{In vitro panning}

Bio-panning was performed as described below. A solution of $64 \mu \mathrm{g} / \mathrm{ml}$ of the $\mathrm{hTfR}$ in $0.1 \mathrm{M}$ $\mathrm{NaHCO}_{3}(\mathrm{pH}$ 8.6) was prepared, $150 \mu \mathrm{l}$ of this solution was added to each well in a 96-well plate and the plates incubated overnight at $4{ }^{\circ} \mathrm{C}$. The coating solution was poured off and blocking buffer bovine serum albumin (BSA) at $5 \mathrm{mg} / \mathrm{ml}$ in $0.1 \mathrm{M} \mathrm{NaHCO} 3$ was added and incubated for $1 \mathrm{~h}$ at $4{ }^{\circ} \mathrm{C}$. The BSA was discarded and each well washed with $0.1 \%(\mathrm{v} / \mathrm{v})$ Tween-20 in $0.1 \%$ TBST and $10 \mu \mathrm{l}$ of original library $\left(2 \times 10^{11}\right.$ plaque-forming units, PFUS) were diluted in 100 $\mu \mathrm{I}$ TBST and added to the plate well for $2 \mathrm{~h}$ at room temperature with gentle agitation. After washing with $0.1 \%$ TBST, the bound phages were eluted with $0.2 \mathrm{M}$ glycine- $\mathrm{HCl}(\mathrm{pH} 2.2)$ and neutralized with $1 \mathrm{M}$ Tris- $\mathrm{HCl}(\mathrm{pH}$ 9.1). Elute phages were amplified in $20 \mathrm{ml}$ Luria Bertani medium containing E. coli ER2738, purified by precipitation with polyethylene glycol PEG/NaCl, which was titrated as described in the standard protocol (NEB), and used for additional rounds of biopanning. The conditions of two additional rounds of selection were performed under more stringent conditions. The concentration and incubation time of $\mathrm{hTfR}$ was gradually reduced (32 $\mathrm{mg} / \mathrm{ml}$ for $1.5 \mathrm{~h}$ and $16 \mathrm{mg} / \mathrm{ml}$ for $1 \mathrm{~h}$ in the 2nd and 3rd rounds, respectively), while the concentration of Tween-20 was gradually increased $(0.3 \%$ and $0.5 \%$ for the 2 nd and $3 r d$ round, respectively).

\section{Enzyme-linked immunosorbent assay (ELISA) for analysing binding ability}

Approximately $1 \times 10^{11}$ pfu of phages were added to each well for $1 \mathrm{~h}$ at room temperature and the unbound phages were washed using the procedure described above for in vitro panning. After washing with $0.1 \%$ TBST, $200 \mu \mathrm{l}$ of horseradish peroxidase (HRP)-anti-M13 (1:5000) was added to each well and incubated at room temperature for $1 \mathrm{~h}$ with agitation. The bound antibody was visualized using 3,3 , 5, 5'tetramethyl- benzidine (TMB) and terminated by $50 \mu \mathrm{l} /$ well of $2 \mathrm{M} \mathrm{H}_{2} \mathrm{SO}_{4}$ after $20 \mathrm{~min}$. The absorbance was measured at $450 \mathrm{~nm}$.

\section{Sequence analysis of selected phages and peptide synthesis}

The phage ELISA binding assay showed six phages with higher OD value than the others, and their sequences were analysed (Shanghai Invitrogen Corporation, China). Homologous analysis was conducted using BioEdit programs. The peptide with the same DNA sequence of the NO.9 phage was synthesised.

\section{Competitive inhibition assay}

Cells were inoculated on 24-well tissue culture plates overnight. They were then washed and incubated in serum-free medium for $3 \mathrm{~h}$ and preincubated with $1 \%(\mathrm{w} / \mathrm{v})$ BSA to block nonspecific binding at room temperature for $1 \mathrm{~h}$. The synthetic peptide $(0.00001 \mathrm{mM}, 0.0001 \mathrm{mM}$, $0.001 \mathrm{mM}, 0.01 \mathrm{mM}, 0.1 \mathrm{mM}$ ) was diluted in PBS and incubated with the cells at $37^{\circ} \mathrm{C}$ for $3 \mathrm{~h}$, then incubated with $1 \times 10^{11} \mathrm{pfu} /$ well of phage clones at $37^{\circ} \mathrm{C}$ for $2 \mathrm{~h}$. The bound phages were recovered and titered.

\section{Cell viability assay}

Cells were seeded in a density of $6 \times 10^{3}$ cells of $200 \mu \mathrm{l}$ per well in 96-well plates and cultivated for $24 \mathrm{~h}$. After being starved in serum-free RPMI 
1640 with $0.4 \%$ (v/v) FBS for $24 \mathrm{~h}$, the cells were treated with serially diluted peptide BP9 (0.00001 mM, $0.0001 \mathrm{mM}, 0.001 \mathrm{mM}, 0.01 \mathrm{mM}$, $0.1 \mathrm{mM})$ for $48 \mathrm{~h}$ and peptide BP9 $(0.001 \mathrm{mM})$ for different time $(6 \mathrm{~h}, 12 \mathrm{~h}, 18 \mathrm{~h}, 24 \mathrm{~h}, 30 \mathrm{~h}, 36 \mathrm{~h}$, $42 \mathrm{~h}$ and $48 \mathrm{~h})$. The viability of cells was determined by the MTT assay. MTT $(20 \mu \mathrm{l})$ was added to each well and incubated with the cells for $4 \mathrm{~h}$. To it was added $150 \mu \mathrm{l} /$ well of dimethyl sulfoxide (DMSO) to dissolve the crystals. Finallt, the absorbance was measured at $490 \mathrm{~nm}$ to determine the number of viable cells.

\section{EGFP-BP9 and EGFP production and purification}

The pEGFP-N1 was used as the template. The forward primer was designed as 5'GGAATTCCATATGCATCACCACCACCACCAC GTGAGCAAGGGCGAGGAGCT-3' with Nde I and histidine-tagged(underline), and the reverse primer was 5'-CCGGAATTCTTAAGAACGATTA TGCAGATGAGCCTTGTACAGCTCGTCCATGC C-3' with short peptide coding region, terminator and EcoR I (underline). The EGFP-BP9 gene was amplified by PCR. The PCR reactions were carried out for 30 cycles: $94{ }^{\circ} \mathrm{C}, 1 \mathrm{~min} ; 58{ }^{\circ} \mathrm{C}, 45$ sec; and $72{ }^{\circ} \mathrm{C}, 1 \mathrm{~min}$. After being digested by Nde I and EcoR I, the EGFP-BP9 fragment was subcloned into Nde I-EcoR I sites of pET-22b, generating the recombinant plasmid $\mathrm{pET}$ 22b/EGFP-BP9. Then, the plasmids were transformed into BL21/DE3 E. coli and expression was induced for $4 \mathrm{~h}$ with $1 \mathrm{mM}$

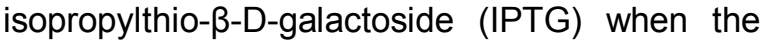
cell culture reached a density of $\mathrm{OD}_{600}=0.6$. The induced cells were harvested and lysed by sonication in binding buffer (1×PBS). Cell lysates were passed over a HisTrap nickel column. The column was washed with wash buffer (1×PBS, $30 \mathrm{mM}$ imidazole, $\mathrm{pH}$ 7.2) and eluted using an imidazole gradient (1×PBS, 90, 120, $150 \mathrm{mM}$ imidazole, $\mathrm{pH}$ 7.2). Purified EGFP and BP9 fusion EGFP were equally fluorescent, indicating that the EGFP-BP9 fusion proteins had the correct conformation and were active in $E$. coli. The purified protein was further assayed by SDS/PAGE, followed by Coomassie staining and Western blot analysis with an EGFP monoclonal antibody (1:500). Protein concentrations were determined with a Pierce BCA Protein Assay Kit (Thermo scientific, 3747 N. Meridian Rd., Rockford, IL 61101 USA) with bovine serum albumin as a standard. The purified EGFP fusion protein was aliquoted in PBS and stored at -80 ${ }^{\circ} \mathrm{C}$.

\section{Binding of the recombinant protein EGFP- BP9}

HepG2 and SMMC-7221 cells $\left(1 \times 10^{5}\right)$ were inoculated in 24-well tissue culture plates. The dishes were washed and incubated in serum-free RPMI-1640 at $37{ }^{\circ} \mathrm{C}$ for $1 \mathrm{~h}$. His-EGFP-BP9 fusion proteins $(8 \mu \mathrm{M})$ were added to the culture medium and incubated at $37{ }^{\circ} \mathrm{C}$ for the indicated time. The cells were washed with PBS to remove non-specific extracellular proteins bound to the cell surface. The cells were suspended in PBS and observed by fluorescence microscope (IX 81, Olympus Corporation, Japan).

\section{Localisation of the recombinant protein EGFP-BP9}

HepG2, SMMC-7221 and L-O2 cells were grown on $15 \mathrm{~mm}$ glass-bottom dishes to $50-75 \%$ confluence. The dishes were washed and incubated in serum-free RPMI- 1640 at $37^{\circ} \mathrm{C}$ for $1 \mathrm{~h}$. Histidine-tagged EGFP-BP9 $(8 \mu \mathrm{M})$ was applied to the cells in serum-free RPMI-1640 at $37^{\circ} \mathrm{C}$ for $1 \mathrm{~h}$. The cells were washed with PBS, then fixed in $4 \%(\mathrm{v} / \mathrm{v})$ formaldehyde for $20 \mathrm{~min}$ at room temperature, and stained for 30 min with 4', 6-diamidino-2-phenylindole (DAPI) to visualise the nuclei. The dishes were mounted in antifade medium. Then cells were then viewed under confocal microscopy (LSM 700, Carl Zeiss Inc., Germany).

\section{Statistical analysis}

All data were presented as mean \pm SEM. All statistical analyses were performed using GraphPad Prism software, version 5.01. Comparison of parameters among two groups was made by Student's test, while one-way ANOVA followed by Tukey's multiple comparison test was used for multiple comparison data. The differences were considered to be significant at $p$ $<0.05$.

\section{RESULTS}

\section{Selection of specific hTfR-binding phage clones}

In this study, Ph.D.--7 ${ }^{\mathrm{TM}}$ Phage Display Peptide Library was used to isolate phages that could specifically bind to hTfR. As shown in Table 1, both phage titre and recovery efficiency were significantly increasing after each round of panning. After three rounds of panning, recovery efficiency was 48 -fold higher (from $2.56 \times 10^{-5}$ to $3.3 \times 10^{-7}$ ) than that of the first round, suggesting that the phage clones specifically bound to hTfR were successfully enriched. In order to identifi the binding ability of selected phage clones, 
Table 1: Enrichment of phages for each round of selection from the phage display library

\begin{tabular}{lcccc}
\hline Round & $\begin{array}{c}\text { hTfR } \\
(\mathbf{m g} / \mathbf{m l})\end{array}$ & $\begin{array}{c}\text { Input phage } \\
(\mathbf{p f u} / \mathbf{m l})\end{array}$ & $\begin{array}{c}\text { Output phage } \\
\text { (pfu/ml) }\end{array}$ & Recovery (\%) \\
\hline 1 & 64 & $1.0 \times 10^{11}$ & $1.3 \times 10^{5}$ & $1.3 \times 10^{-6}$ \\
2 & 32 & $4.4 \times 10^{11}$ & $1.95 \times 10^{6}$ & $4.43 \times 10^{-6}$ \\
3 & 16 & $1.5 \times 10^{11}$ & $9.4 \times 10^{6}$ & $6.26 \times 10^{-5}$ \\
\hline & $*$ pfu, Plaque forming unit & & &
\end{tabular}

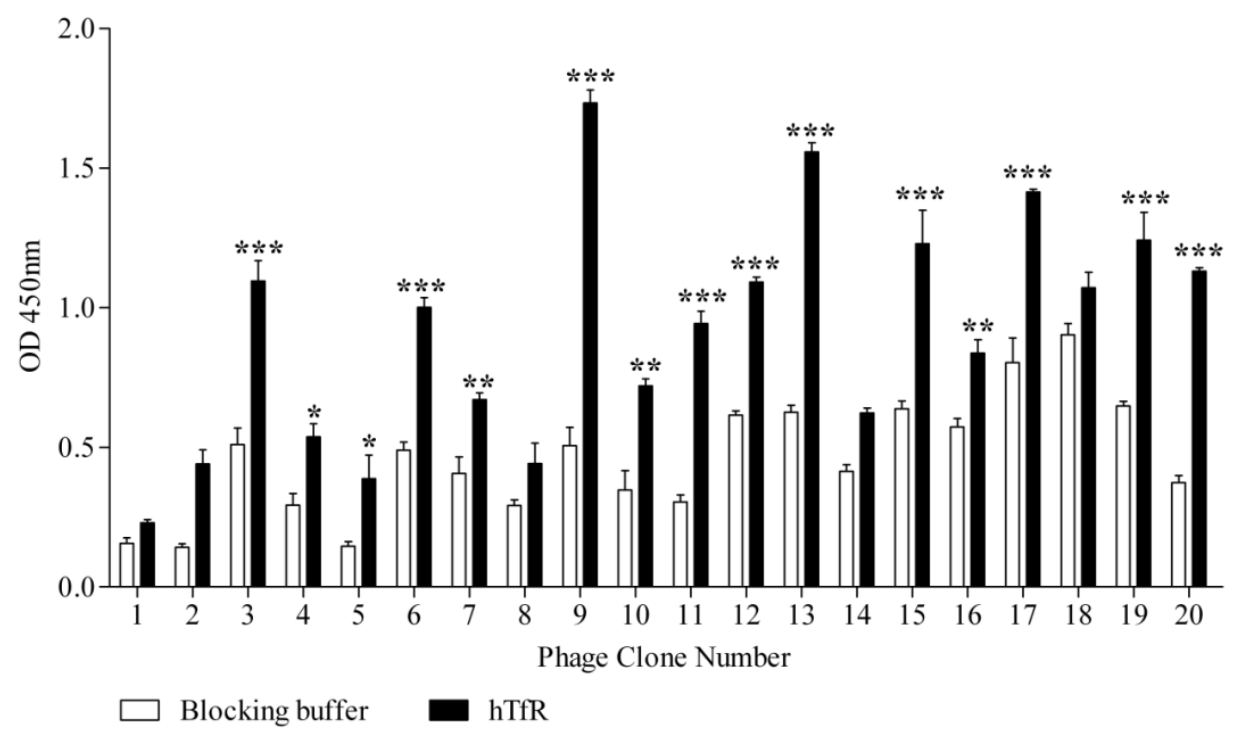

Figure 1: Appraisal of twenty phage clones' binding ability by ELISA. The blocking buffer without hTfR was used as negative control. Data presented are the mean O.D. values ( \pm S.D.) of triplicate samples; $* p<0.05, * * p<$ $0.01, * * * \mathrm{p}<0.001$ versus blocking buffer sample

Table 2: Amino acid sequences of specific hTfR-binding peptides and compare with Tf

\begin{tabular}{llllll}
\hline Phage no.. & Peptide no.. & $\begin{array}{l}\text { Seuqence } \\
\text { (N-C) }\end{array}$ & Similarities to Tf & Theoretical PI & GRAVY \\
\hline P3 & BP3 & HAlYPRH & 0.0014327 & 8.76 & -1.071 \\
P6 & BP6 & FLHSAGS & 0.0042980 & 6.74 & 0.457 \\
P9 & BP9 & AHLHNRS & 0.0042980 & 9.81 & -1.371 \\
P11 & BP11 & VPRSMEM & 0.0042980 & 5.97 & -0.343 \\
P15 & BP15 & HENQTRQ & 0.0014327 & 6.75 & -3.200 \\
P20 & BP20 & MPVPRLL & 0.0042980 & 9.50 & 0.857 \\
& Tf $_{651-657^{\circ}}$ & FRSETKD & & 6.07 & -2.014 \\
& $\mathrm{Tf}^{\circ}$ & & & 6.81 & -0.377 \\
\hline
\end{tabular}

${ }^{a}$ Bold letters show the conserved motifs; ${ }^{\circ}$ One segments of Tf that shows partial homology with the peptides of the selected phage clones.

twenty independent phage clones which were randomly picked after the third panning were tested by ELISA. As shown in Fig 1, six clones had showed high bindng ability to hTfR (clones 3 , $6,9,11,15,20$ ) when compared to negative control, suggesting that they may have higher affinity for hTfR than the other clones. Then we selected the six clones for sequencing.

\section{DNA sequence analysis and property prediction of selected phage clones}

The hTfR binds to ligand transferrin (Tf) and provides iron to maintain cellular survival.
Therefore, the amino acid sequences of selected peptides were compared with the Tf. As shown in Table 2, most sequences consisted of basic amino acids. The phage clone P9 (peptide was named BP9) as well as P11 showed the highest sequence similarity to $\mathrm{Tf}(0.004298$, PAM250 Matrix). They contain 2 identical amino acids (RS) to the peptide of the site 651-657 (FRSETKD) of Tf (Genebank ID AAB22049). In the physiological condition, BP9, BP11 and $\mathrm{Tf}_{651}$. 657 all carry the negative charges and they are all the hydrophilic peptides. Moreover, the hydrophobic profile of BP9 was similar to the peptide $\mathrm{Tf}_{651-657}$. Taken together, these data 
suggest that the peptide BP9 sharing 2 identical amino acids to the ligand Tf may bind hTfR via electrostatic interactions and may interrupt hTfR binding to its ligand $\mathrm{Tf}$. Consequently, the peptide BP9 was chosen for further study.

\section{Competitive inhibition assay and inhibition of cell proliferation}

A peptide competitive inhibition assay was performed to discover whether the synthetic peptide BP9 and the selected P9 phage clone (which displaying peptide BP9 sequence) competed for the same binding site. The BP9 peptide was used as the inhibitor of P9 phage clone. In this work, we chose the HepG2 and SMMC-7221 cells because both them are liver cancer cells and over-expressing TfR $[14,15]$. As shown in Fig 2A, with an increase in the concentration of BP9, the titre of the phages recovered from the HepG2 and SMMC-7221 cells decreased and the inhibition rate gradually increased. At $0.1 \mathrm{mM}$, the inhibition ratio for the binding of P9 phages to HepG2 and SMMC-7221 cells was approximate $67 \%$ and $57 \%$, respectively, which demonstrated BP9 strongly inhibited the binding of P9 phages to HepG2 and SMMC-7221 cells. However, BP9 had no effect on the binding of the M13KE phages to HepG2 and SMMC-7221 cells. In addition, BP9 also had no effect on the binding of the P9 phages to L-O2 cells, which were normal liver cells and lack of TfR. The P9 phages binding to HepG2 and SMMC-7221 cells was mediated by BP9, indicating that they competed for the same site of TfR.

To determine whether BP9 could inhibit the proliferation of tumour cells, we had used an MTT assay to investigate the effects of BP9 on the proliferation of HepG2, SMMC-7221 and L$\mathrm{O} 2$ cells. The starved cells were treated with various concentrations of BP9 for $48 \mathrm{~h}$ (Fig 2B) and $0.001 \mathrm{mM}$ (Fig 2C) of BP9 for different time. BP9 had a dose-dependent and time-dependent inhibitory effect on the proliferation of HepG2 and SMMC-7221 cells. When the concentration of BP9 was $0.1 \mathrm{mM}$, the inhibition ratio was approximate $70 \%$ and $77 \%$ for HepG2 and SMMC-7221 cells, respectively, and when the cells were treated with $0.001 \mathrm{mM}$ of BP9 for $48 \mathrm{~h}$, the inhibition ratio was approximate $85 \%$ and 81 $\%$ for HepG2 and SMMC-7221 cells, respectively. However, BP9 had no effect on the L-O2 cells, implied that BP9 could target specifically with TfR and may interrupt TfR binding to its ligand Tf.
EGFP-BP9 and EGFP production, purification and binding on tumour cells

In order to further research whether the BP9 peptide could mediate other macromolecules to combine with TfR, the DNA sequence coding for peptide BP9 were fused with enhanced green fluorescence protein (EGFP) by PCR and inserted into expressing vector $p E T-22 b$. After expression and purification, EGFP-BP9 fusion protein was obtained. The purified products were analysed by SDS-PAGE and Western blot test (Fig 3A). The EGFP fusion proteins migrated at the expected sizes.

To confirm whether EGFP-BP9 purified under the above-mentioned conditions could bind easily to tumour cells, a fluorescence microscope was used for direct observation. As shown in Fig 3B, the fluorescence was readily detected in the HepG2 and SMMC-7221cells treated with EGFPBP9, whereas the control EGFP failed under the same condition. Therefore, the EGFP-BP9 possessed cellular binding ability to tumour cells. To investigate whether the EGFP-BP9 could bind to the cells over-expressing TfR and gain entry via the endocytic pathway, HepG2, SMMC-7221 and $\mathrm{L}-\mathrm{O} 2$ cells were examined by confocal microscopy. As shown in Fig 3C, the HepG2 and SMMC-7221 cells showed bright green fluorescence staining around the cell membrane. However, the L-O2 cells with lack of TfR only showed blue fluorescence background staining. These results suggested that EGFP-BP9 had selectivity and specificity abilities to HepG2 and SMMC-7221 cells which over-expressing TfR.

\section{DISCUSSION}

Drug-resistant metastatic tumours and side effects are major limitations of conventional cancer therapy, such as irradiation and chemotherapy $[16,17]$, necessitating the search for novel tumour-targeting agents. Transferrin receptors over-expressed in tumour cells, therefore, use the transferrin receptor as a target and the phage display technique to screen and obtain the transferrin receptor-specific binding short peptides, which may be expected to become the new tumour-targeting molecules.

In the present work, we used a Ph.D. $-7^{\mathrm{TM}}$ phage display library to screen TfR special binding peptides. In the process of the selection, screening conditions were gradually strict, the TfR concentration was gradually reduced, the Tween-20 concentration was gradually increased, and the elution time was extended. Through three rounds of selection, the phage 

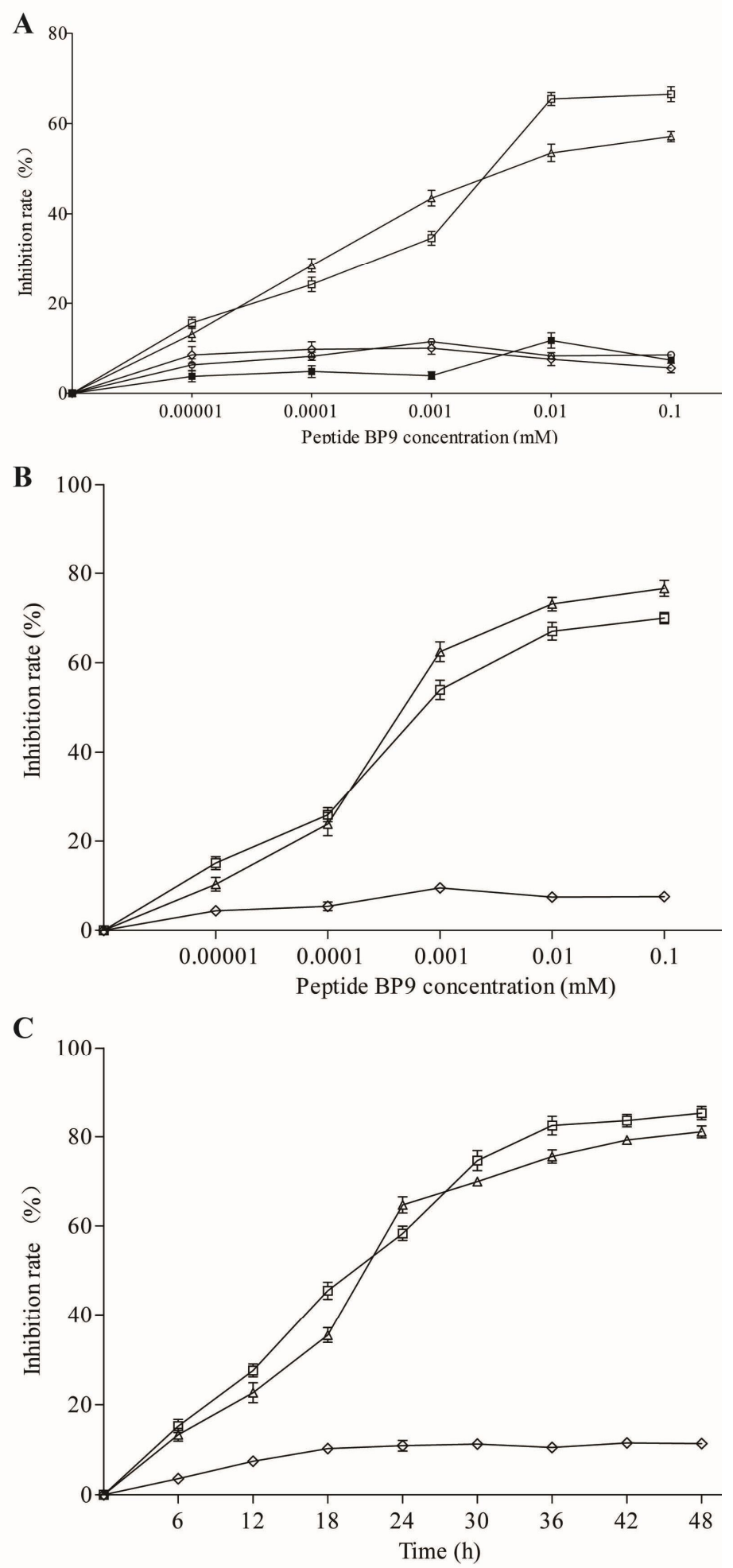

Figure 2: Competitive inhibition assay and inhibition of cells' proliferation. (A) Competitive inhibition assay of the P9 phage clone binding to the cells by the synthetic peptide BP9 ( $\square=$ HepG2 cells/peptide BP9/P9 phage, $\triangle=$ SMMC-7221 cells/peptide BP9/P9 phage, $\diamond=$ HepG2 cells/peptide BP9/M13 phage, $0=$ SMMC-7221 cells/peptide BP9/M13 phage, $\boldsymbol{-}=\mathrm{L}-\mathrm{O} 2 \mathrm{cells} /$ peptide BP9/P9 phage). (B) Concentration dependent inhibition of peptide BP9 on the proliferation of cells ( $\square=$ HepG2 cells, $\triangle=$ SMMC-7221 cells, $\diamond=\mathrm{L}-\mathrm{O} 2$ cells). (C) Time dependent inhibition of peptide BP9 $(0.001 \mathrm{mM}$ ) on the proliferation of cells ( $\square=$ HepG2 cells, $\triangle=$ SMMC-7221 cells, $\diamond=\mathrm{L}-\mathrm{O} 2$ cells). The independent experiments were repeated four times. Data presented are the mean absorbance $( \pm$ S.D.) of four samples. 


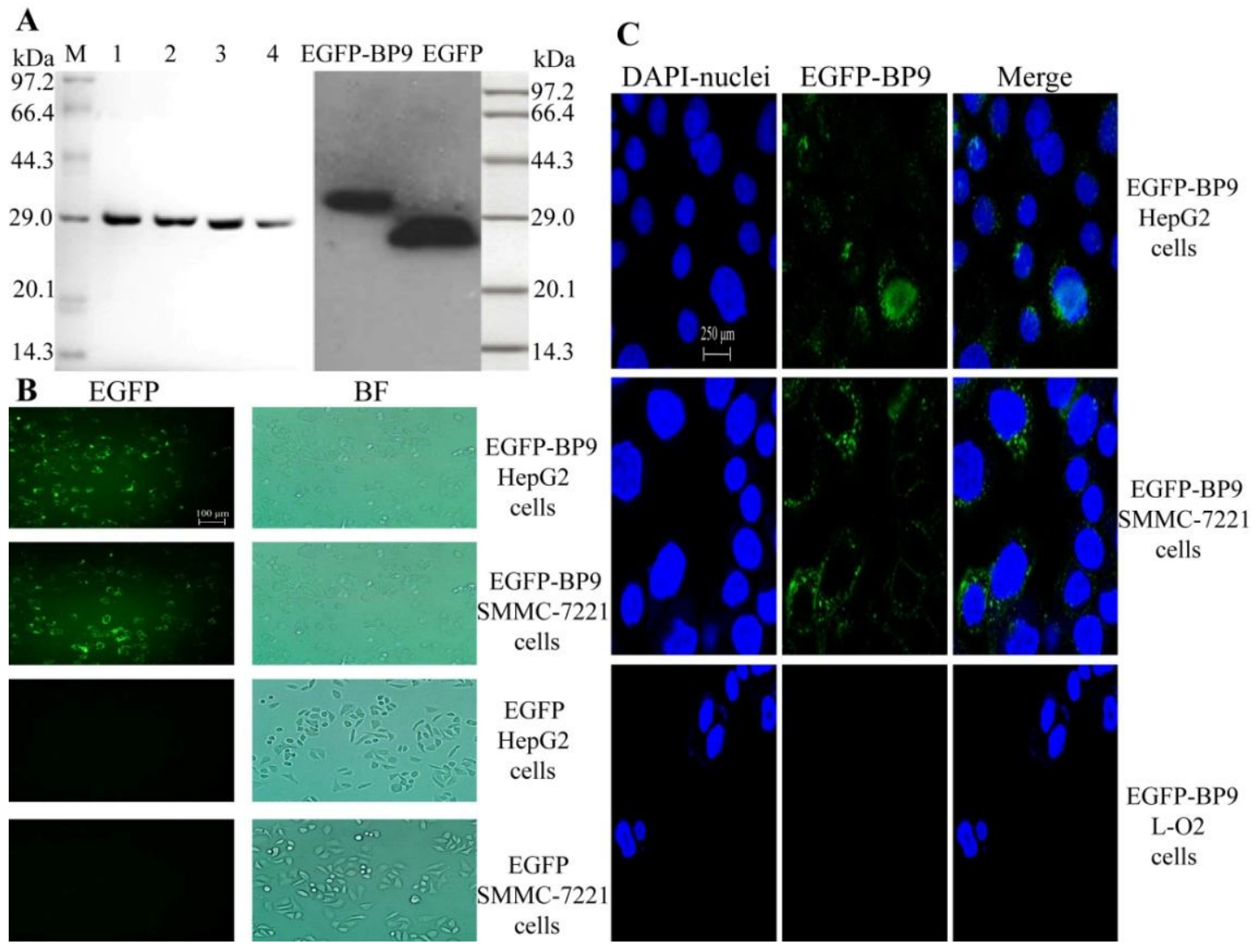

Figure 3: (A) SDS-PAGE and Western blot analyses of purified His-EGFP-BP9 fusion protein. Left panel, Coomassie Blue staining SDS-PAGE gel (Lane M, Molecular markers; lane 1, 2, purified His-EGFP-BP9; lane 3, 4, purified control His-EGFP); right panel, Western blot using anti-EGFP antibody; (B) Binding of EGFP-BP9 fusion protein on tumour cells. Cells were observed by fluorescence microscopy (Magnification $\sim \times 100$ ). (C) Localisation of EGFP-BP9 fusion protein on tumour cells. Cells were observed by confocal laser microscopy (Magnification $\sim \times 40$ ).

clone P9 showed the highest affinity to TfR, examined by ELISA. A peptide competitive inhibition assay showed that when the synthetic peptide was pre-incubated with HepG2 and SMMC-7221 cells, the binding of phage P9 to cells was inhibited in a dose-dependent manner. Cell viability assay also had showed that BP9 could inhibit the proliferation of the HepG2 and SMMC-7221 cells.

In order to further research whether the P9 phage display seven peptide can mediate other macromolecules to combine with TfR, P9 gen were fused with EGFP and connected to $p E T$ 22b. After expression and purification, EGFPBP9 fusion protein was obtained. Through fluorescence microscopy, we found that EGFPBP9 could bind to HepG2 cells and SMMC-7221 cells. However, the control groups could not. Further confocal laser microscopy was used to observe the localisation, we found fluorescence distributed mainly around the cell membrane, but we did not see the obvious cell plasma positive. These results show that the EGFP-BP9 fusion protein can combine with TfR on HepG2 cells and SMMC-7221 cells, and that BP9 has the ability to mediate other molecules to bind to TfR.

\section{CONCLUSION}

This study describes an in vitro panning process used to select a peptide (designated BP9) capable of specifically binding to TfR. Peptide BP9 can inhibit the proliferation of the tumour cells over-expressing TfR and the DNA sequence coding for peptide BP9 is also able to target a macromolecule (EGFP) to combine with TfR. This suggests that the peptide BP9 may possess potential applications in cancer therapy.

\section{ACKNOWLEDGMENT}

This work was supported by a grant from the Guangzhou Science and Technology Project (2010Y1-C541) and 211 Project. The first two named authors contributed equally to this work and should be considered co-first authors. 


\section{REFERENCES}

1 Sidhu SS. Phage display in pharmaceutical biotechnology. Curr Opin Biotech 2000; 11: 610-616.

2 Arap W, Pasqualini R, Ruoslahti E. Cancer treatment by targeted drug delivery to tumor vasculature in a mouse model. Science 1998; 279: 377-380.

3 Li Z, Zhao R, Wu X, Sun Y, Yao M, Li J, Xu Y, Gu J. Identification and characterization of a novel peptide ligand of epidermal growth factor receptor for targeted delivery of therapeutics. FASEB $J$ 2005; 19: 1978-1985.

4 Zhang J, Spring H, Schwab M. Neuroblastoma tumor cellbinding peptides identified through random peptide phage display. Cancer Lett 2001; 171: 153-164.

5 Zitzmann S, Ehemann V, Schwab M. Arginine-glycineaspartic acid (RGD)-peptide binds to both tumor and tumor-endothelial cells in vivo. Cancer Res 2002; 62: 5139-5143

6 Pasqualini $R$, Koivunen $E$, Kain $R$, Lahdenranta J, Sakamoto M, Stryhn A, Ashmun RA, Shapiro LH, Arap $W$, Ruoslahti E. Aminopeptidase $N$ is a receptor for tumor-homing peptides and a target for inhibiting angiogenesis. Cancer Res 2000; 60: 722727.

7 Sugahara KN, Teesalu T, Karmali PP, Kotamraju VR, Agemy L, Greenwald DR, Ruoslahti E. Coadministration of a tumor-penetrating peptide enhances the efficacy of cancer drugs. Science 2010; 328: 1031-1035.

8 Hai TZ, Hui CL, Zheng WL, Chang HG. A tumor-penetrating peptide modification enhances the antitumor activity of endostatin in vivo. Anti-Cancer Drug 2011; 22: 409-415.
9 Wu Y, Cain HC, Choy L, Hagenbeek TJ, de Leon GP, Chen $Y$, Finkle $D$, Venook $R, W u X$, Ridgway J, et al. Therapeutic antibody targeting of individual Notch receptors. Nature 2010; 464: 1052-1057.

10 Moos T, Morgan EH. Transferrin and transferrin receptor function in brain barrier systems. Cell Mol Neurobiol 2000; 20: 77-95.

11 Xu Z, Gu W, Huang J, Sui H, Zhou Z, Yang Y, Yan Z, Li Y. In vitro and in vivo evaluation of actively targetable nanoparticles for paclitaxel delivery. Int $\mathrm{J}$ Pharm 2005; 288: 361-368.

12 Li X, Ding L, Xu Y, Wang Y, Ping Q. Targeted delivery of doxorubicin using stealth liposomes modified with transferrin. Int J Pharm 2009; 373: 116-123.

13 Lee JH, Engler JA, Collawn JF, Moore BA. Receptor mediated uptake of peptides that bind the human transferrin receptor. Eur J Biochem 2001; 268: 2004-2012.

14 Qing Y, Shuo W, Zhihua W, Huifen Z, Ping L, Lijiang L, Xiaorong Z, Liming C, Daiwen $X, Y u H$, et al. The in vitro antitumor effect and in vivo tumor-specificity distribution of human-mouse chimeric antibody against transferrin receptor. Cancer Immunol Immun 2006; 55: 1111-1121.

15 Ciechanover A, Schwartz AL, Dautry-Varsat A, Lodish HF. Kinetics of internalization and recycling of transferrin and the transferrin receptor in a human hepatoma cell line. Effect of lysosomotropic agents. J Bio Chem 1983; 258: 9681-9689.

16 Zhang JT, LiU Y. Use of comparative proteomics to identify potential resistance mechanisms in cancer treatment. Cancer Treat Rev 2007; 33: 741-756.

17 Beretta GL, Perego P, Zunino F. Mechanisms of cellular resistance to camptothecins. Curr Med Chem 2006; 13: 3291-3305 